\title{
Persistence survey of Toxic Shock Syndrome toxin-1 producing Staphylococcus aureus and serum antibodies to this superantigen in five groups of menstruating women
}

Jeffrey Parsonnet ${ }^{1 \dagger}$, Melanie A Hansmann ${ }^{3 *}$, Jon L Seymour ${ }^{3 \dagger}$, Mary L Delaney ${ }^{2 \dagger}$, Andrea M DuBois ${ }^{2 \dagger}$, Paul A Modern ${ }^{1 \dagger}$, Michaelle B Jones ${ }^{3+}$, John E Wild ${ }^{4 \dagger}$, Andrew B Onderdonk ${ }^{2+}$

\begin{abstract}
Background: Menstrual Toxic Shock Syndrome (mTSS) is thought to be associated with the vaginal colonization with specific strains of Staphylococcus aureus TSST-1 in women who lack sufficient antibody titers to this toxin. There are no published studies that examine the seroconversion in women with various colonization patterns of this organism. Thus, the aim of this study was to evaluate the persistence of Staphylococcus aureus colonization at three body sites (vagina, nares, and anus) and serum antibody to toxic shock syndrome toxin-producing Staphylococcus aureus among a small group of healthy, menstruating women evaluated previously in a larger study.

Methods: One year after the completion of that study, 311 subjects were recalled into 5 groups. Four samples were obtained from each participant at several visits over an additional 6-11 month period: 1) an anterior nares swab; 2) an anal swab; 3) a vagina swab; and 4) a blood sample. Gram stain, a catalase test, and a rapid S. aureusspecific latex agglutination test were performed to phenotypically identify S. aureus from sample swabs. A competitive ELISA was used to quantify TSST-1 production. Human TSST-1 lgG antibodies were determined from the blood samples using a sandwich ELISA method.
\end{abstract}

Results: We found only $41 \%$ of toxigenic S. aureus and $35.5 \%$ of non-toxigenic nasal carriage could be classified as persistent. None of the toxigenic $S$. aureus vaginal or anal carriage could be classified as persistent. Despite the low persistence of $S$. aureus colonization, subjects colonized with a toxigenic strain were found to display distributions of antibody titers skewed toward higher titers than other subjects. Seven percent (5/75) of subjects became seropositive during recall, but none experienced toxic shock syndrome-like symptoms.

Conclusions: Nasal carriage of $S$. aureus appears to be persistent and the best predicator of subsequent colonization, whereas vaginal and anal carriage appear to be more transient. From these findings, it appears that antibody titers in women found to be colonized with toxigenic $S$. aureus remained skewed toward higher titers whether or not the colonies were found to be persistent or transient in nature. This suggests that colonization at some point in time is sufficient to elevate antibody titer levels and those levels appear to be persistent. Results also indicate that women can become seropositive without experiencing signs or symptoms of toxic shock syndrome.

\footnotetext{
* Correspondence: hansmann.ma@pg.com

+ Contributed equally

${ }^{3}$ The Procter \& Gamble Company, 6010 Center Hill Ave., Cincinnati, Ohio,

USA

Full list of author information is available at the end of the article
} 


\section{Background}

Toxic shock syndrome (TSS) is a systemic disease of acute onset characterized by fever, hypotension, myalgia, rash, multiple-organ failure, and late desquamation of hands and feet [1]. It is associated with colonization with toxic shock syndrome toxin-1 (TSST-1)-producing $S$. aureus in the vagina during menstruation, or at other sites due to complications of a staphylococcal infection (especially skin or respiratory tract), or as a complication of a surgical procedure or other medical condition $[2,3]$. TSST -1 , the most common such toxin, causes the vast majority (95\%) of cases associated with menstruation and $40-60 \%$ of the nonmenstrual cases [4,5].

Menstrual Toxic Shock Syndrome (mTSS) has been associated with menstruation and tampon use. Despite the very low incidence of mTSS, the disease remains of interest, because tampons are widely used. Czerwicnski [6] reported in a recent descriptive research study that approximately $80 \%$ of the study participants (women under of the age of 41 from California) used tampons at some point during menstruation. It has also been reported recently that about $70 \%$ of women in the United States of America (USA), Canada and much of Western Europe use tampons at some point during menstruation [7].

Menstrual TSS is generally thought to be caused by $S$. aureus TSST-1 in a susceptible host $[8,9]$. TSST-1 is considered a superantigen (SAg), a class of very potent immune stimulators that interact with the immune system in a way that is different from conventional antigens. As a result, the magnitude of immune stimulation by a SAg is usually 10-500,000 fold higher than with convention antigens. This exaggerated release of inflammatory cytokines is responsible for the clinical signs of illness associated with these toxins $[10,11]$. Individuals who lack neutralizing antibodies to a SAg are at a higher risk of developing severe systemic disease with hypotension and organ failure, particularly if they happen to be high responders to these specific SAgs [11-13].

Four factors are thought to be required for the development of the mTSS: (1) vaginal colonization with a toxigenic strain of $S$. aureus; (2) production of TSST-1; (3) penetration of a sufficient concentration of TSST-1 across the epithelium to cause the disease; and (4) absence or insufficient titers of neutralizing antibody to the toxin. Vaginal colonization by toxigenic $S$. aureus has been reported in $1 \%$ to $4 \%$ of the populations studied [[14-18]; Parsonnet J, Tosteson A, Modern P, Wissemann K. Wissemann: Abstr. $33^{\text {rd }}$ Intersci. Conf. Antimicrob. Agents Chemother. abstr. 1327, 1993]. Invitro studies have shown that the production of TSST-1 by toxigenic $S$. aureus is dependent on environmental factors such as the partial pressure of $\mathrm{O}_{2}$ and $\mathrm{CO}_{2}$ [19], as well as other factors such as iron concentration, $\mathrm{pH}$ and temperature [20-22]. Once produced, TSST-1 must then penetrate the vaginal mucosal surface. It has been shown that topical exposure to this superantigen in an ex vivo model causes an increase in mucosal permeability in a non-dose-dependent manner [23]. If TSST-1 is capable of penetrating the epithelial surfaces, it can be neutralized effectively by anti-TSST-1 antibodies [24]. Bergdoll has shown that individuals who have developed TSS tend to have lower sera antibody titers to TSST-1 than healthy individuals [8]. Studies have also shown that sera antibody titers increase with age [25], and that the vast majority $(87-100 \%)$ of the adult population has developed sera antibody to TSST-1 [[14,15,26,25]; Vergeront JM, Blouse LE, Crass, BA, Stolz SJ, Bergdoll MS, Davis JP: Abstr. Intersci. Conf. Antimicrob. Agents Chemother, abstr. 610, 1984].

Results from our previous prevalence study of 3012 healthy, menstruating women [14] supported our hypothesis that the low incidence of mTSS is a result of two factors: 1) the majority of women colonized with $S$. aureus are colonized by non-toxigenic strains, and 2) most women have positive antibody titers to TSST- 1 . We found $75 \%$ of S. aureus carriers (or $20 \%$ of the population) were colonized with non-toxigenic $S$. aureus and only $1 \%$ of the study population was colonized vaginally with toxigenic strains of $S$. aureus. Positive antibody prevalence, defined as titer $\geq 1: 32$, was high in the general study population (85\%), and even higher among subjects colonized by toxigenic $S$. aureus in the nose (98\%), vagina (97\%), or anus (100\%). Only eight percent (8\%) of the study population were classified as antibody "negative," exhibiting antibody titer $\leq 1: 4$.

This follow up study was designed to determine the persistence of $S$. aureus and serum antibody among groups of menstruating women recalled from the previous study. Negative controls for S. aureus and serum antibody were included to determine whether subjects became $S$. aureus carriers or seroconverted during recall. Previous studies in this area have focused on the persistence of nasal carriage of $S$. aureus among different populations [27-29], as well as the classification [27], and prediction $[30,31]$ of nasal carrier states. To our knowledge, this is the first published study to evaluate the persistence of serum antibody and $S$. aureus carriage at two additional body sites (anus and vagina).

\section{Methods \\ Subjects}

Approximately one year after completion of the previous study of 3012 subjects, published in 2005 by Parsonnet, et al., [14] subjects, a smaller subgroup was recalled and 
Table 1 Description of subject groups enrolled in follow up study

\begin{tabular}{|c|c|c|c|c|c|}
\hline $\begin{array}{l}\text { Group } \\
\text { No. }\end{array}$ & Description & $\begin{array}{c}\text { Body site where } \\
\text { S. aureus detected } \\
\text { in Parsonnet } 2005 \\
\text { study }^{\mathrm{a}}\end{array}$ & $\begin{array}{l}\text { Ab present in } \\
\text { Parsonnet } 2005 \\
\text { study }^{\mathrm{b}}\end{array}$ & $\begin{array}{l}\text { No. of subjects } \\
\text { enrolled }^{\mathrm{c}}\end{array}$ & $\begin{array}{l}\text { No. of subjects } \\
\text { completing all } \\
\text { visits }\end{array}$ \\
\hline 1 & Carriers of SA TSST-1(+) & Vagina & Yes or No & 14 & 11 \\
\hline 2 & Carriers of SA TSST-1(+) & Nose or anus & Yes & 78 & 64 \\
\hline 3 & Carriers of SA TSST-1(-) & Any site & Yes & 69 & 49 \\
\hline 4 & Non-carriers & None & Yes & 75 & 58 \\
\hline 5 & $\begin{array}{l}\text { Negative Ab control } \\
\text { (Carriers or Non-carriers) }\end{array}$ & Any site & No & 75 & 61 \\
\hline
\end{tabular}

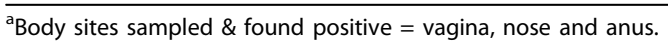

${ }^{\text {b }}$ Yes = anti-TSST- 1 antibody titers $\geq 1: 32 ;$ No = anti-TSST-1 titers $\leq 1: 4$.

c Subjects who returned for at least one visit during follow up.

followed for an additional 6-11 months, depending upon the group assignment (Table 1). Groups consisted of both vaginal and non-vaginal carriers of toxigenic TSST-1 - producing S. aureus, carriers of non-toxigenic $S$. aureus and two control groups: non-carriers of S. aureus and subjects who were antibody negative.

Groups 3-5 were scheduled for three equally spaced visits. Groups 1 and 2 were scheduled for four equally spaced visits because of our interest in toxigenic $S$. aureus colonization. Subjects were recalled from five geographically separate sites in North America by Hill Top Research Inc. in Cincinnati, OH; East Brunswick, NJ; St. Petersburg, FL; Scottsdale, AZ and Winnipeg, Manitoba, Canada. Recall was based on a target enrollment of 75 participants in Groups 2-5. Target enrollment for Group 1 was the total number of subjects that met the criteria $(\mathrm{n}=33)$. The total number of subjects who met the Group 1 criteria (S. aureus TSST-1 vaginal carriers) from the previous study was very low (33 subjects/3012 total subjects). Every attempt was made to recruit all Group 1 subjects. Some of the subjects could not be located and others did not wish to participate in this follow up study.

Women were eligible for enrollment in this study if they completed the previous study and continued to meet the original enrollment criteria [14] on recall. Briefly, the criteria required subjects to be between the ages of 13-40, to be in good health, to have regular menstrual cycles (length between 21 and 35 days), to use tampons at least occasionally, and to have refrained from bathing or other activities which could alter the vaginal environment within the 2 hours prior to their scheduled visit (Table 2).

Subjects read and signed a revised informed consent document prior to the collection of any information or clinical sampling. Subjects were removed from the study if they failed to meet the inclusion criteria and satisfied any of the exclusion criteria at any time during the study.

\section{Study conduct}

Study protocol and informed consent document were reviewed and approved by Hill Top's Institutional Review Board. Informed consent was obtained from all subjects participating in the previous prevalence study. This follow up study was conducted from February, 29, 2000 to March 29, 2001.

Procedures, methods and materials used in this study were identical to those used in the previously published study [14]. Procedures and methods are summarized in the following sections.

\section{Sample collection}

Trained personnel at each recruitment site collected the following samples from each subject: 1) an anterior nares swab (penetration of 0.5-1.0 inch); 2) an anal swab (approximately 0.5 to 1 inch past the anal sphincter); 3 ) a midpoint vagina swab (approximately 3 - 4 inches into the vagina) and 4) a blood sample.

\section{Sample Handling}

Swabs (nasal, anal and vaginal) were shipped overnight to Harvard Medical School, Channing Laboratory (Boston, MA) for isolation and phenotypic identification of S. aureus and TSST-1 production. Collected serum was shipped overnight to Dartmouth-Hitchcock Medical Center (Lebanon, NH) for analysis of TSST-1 antibodies. Clinical laboratories were supplied with subject number, subject's initials and area of the body sampled.

\section{Swab analyses}

Using standard, published phenotypic methods for isolation of S. aureus from human samples, [14,32,33] nasal and anal swabs were streaked onto a mannitol salt agar (MSA) plate, vaginal swabs were dispersed into Amies medium with agar, streaked onto a MSA plate, incubated for $48 \mathrm{hrs}$ and visualized for characteristic morphology of $S$. aureus. Colonies were enumerated, isolated onto plates containing trypticase soy agar with 
Table 2 Inclusion/Exclusion Criteria for the previous and this follow up study

\begin{tabular}{ll}
\hline Inclusion & Exclusion \\
\hline $\begin{array}{l}\text { Had a regular menstrual cycles (minimum of } 21 \text { days } \\
\text { and maximum of } 35 \text { days); }\end{array}$ & Had participated in another clinical study \\
Had used tampons at least occasionally & $\begin{array}{l}\text { Were pregnant, actively trying to get pregnant or } \\
\text { suspected they were pregnant } \\
\text { Had a gynecological abnormality as judged by the } \\
\text { study medical personnel } \\
\text { prior to their scheduled visits }\end{array}$ \\
$\begin{array}{l}\text { Refrained from using douching substances, vaginal } \\
\text { medications, suppositories, feminine sprays, genital } \\
\text { wipes, or contraceptive spermacides for } 48 \text { hours prior } \\
\text { to their scheduled visits }\end{array}$ & 6 weeks \\
& \\
& $\begin{array}{l}\text { Had been medically diagnosed as having diabetes, } \\
\text { kidney failure, hepatitis, AlDS (HIV positive) or } \\
\text { toxic shock syndrome }\end{array}$ \\
& $\begin{array}{l}\text { Were currently taking (within the last } 30 \text { days) } \\
\text { immunosuppressive drugs, chemotherapy, } \\
\text { systemic antimicrobial drugs, or antifungals or } \\
\text { antimicrobials to treat a vaginal infection }\end{array}$ \\
\end{tabular}

$5 \%$ sheep blood, and incubated for 24 hrs. Gram stain, a catalase test, and a rapid $S$. aureus-specific latex agglutination test were performed to phenotypically identify $S$. aureus.

\section{Determination of TSST-1 production}

A previously validated and published competitive ELISA was used to quantify TSST-1 production using a membrane over agar protocol with subsequent TSST-1 quantification by ELISA [14,32,34]. After being positively identified as $S$. aureus, a heavy suspension was developed in PBS and $200 \mathrm{ul}$ of the suspensions was placed on a dialysis membrane covering a $60 \times 15 \mathrm{~mm}$ Brain Heart Infusion Petri plate. The plates were incubated in a humid chamber at $37 \mathrm{deg} C$ for $24 \mathrm{~h}$, washed with 1.5 $\mathrm{mL}$ of PBS and collected by centrifugation. Historical samples of $S$. aureus that were known not to produce TSST -1 and others that produced TSST -1 served as negative and positive controls, respectively. All $S$. aureus strains isolated at the Channing Laboratory were shipped to Dartmouth-Hitchcock Medical Center for confirmatory analyses using ELISA and/or PCR techniques [35].

\section{Serum analyses}

An indirect antibody capture assay was used to determine the serum anti-TSST-1 IgG antibody titer of each subject. This method was used in the large seroprevalence study published by Parsonnet, et al., in 2005 [14]. Briefly, non-immune human serum from healthy volunteers and Human Immune Glogulin Intravenous IgG served as negative and positive controls, respectively. Microtiter plates coated with TSST-1 $(0.5 \mu \mathrm{g} / \mathrm{mL})$ and sera were diluted serially in phosphate buffered saline, incubated overnight, treated with goat anti-human IgG/ alkaline phosphatase, incubated, washed, and then treated with an enzyme substrate $[1 \mathrm{mg} / \mathrm{mL}$ p-nitrophenyl phosphate in $10 \%$ diethanolamine buffer]. Plates were incubated at $24^{\circ} \mathrm{C}$ until positive control wells reached an optical density (OD) of 1.0 (405 nm). The OD of sample solutions was determined and dilution curves were plotted for each sample. The threshold OD was determined previously by testing sera from patients with TSS caused by TSST-1. All such sera (diluted 1:4) yielded an OD of less than 0.2 times that of the positive control.

The antibody titer of each sample was calculated as the highest dilution yielding an OD greater than that of the positive control. Samples with titers of $\leq 1: 4$ were classified as being "negative" for antibody and those with titers of $\geq 1: 32$ were classified as "positive." These classifications are based on previous clinical experience with several hundred patients with either mTSS or TSST-1-induced nonmenstrual TSS. Of these patients, greater than $90 \%$ had a titer of $\leq 1: 4$ and $100 \%$ had a titer of $<1: 32$ (Parsonnet, unpublished observations). Titers of 1:8 and 1:16 were classified as "intermediate" (i.e., likely to contain antibodies to TSST-1, but may not be associated with protection from mTSS). Dilution curves were scrutinized by two observers, with concordance required for there to be a final antibody determination. Because the assay yielded a quantitative result (not subject to observer bias), there was no inter- or intra-observer variation in the antibody result.

\section{Classification of S. aureus carriage}

Carriage was classified as transient, intermittent or persistent based on calculations of carrier index in order to compare results to others in the literature [27]. Subjects were included if they had completed a minimum of three post initial visits. The carrier index (CI) was calculated as the number of swabs with positive culture of 
$S$. aureus relative to the total number of swabs taken $x$ 100. Subjects with carrier indices of $0-24 \%$ were classified as transient, between $25-74 \%$ were classified as intermittent, and $75-100 \%$ were considered persistent carriers. This classification was an arbitrary designation and was use to simply explain the data.

\section{Results}

\section{Demographics of subjects}

The geographical distribution of the 311 subjects enrolled in the study was similar to that for the previous study [14], except that the percentage of participants from Arizona, Florida and Manitoba was slightly higher. The distribution was: Arizona, 24\% $(n=76)$; Florida, $22 \%(n=68)$; New Jersey $13 \%(n=41)$; and Ohio, $16 \%$ $(n=50)$ (United States) and Manitoba, 24\% $(n=76)$ (Canada). The mean age of subjects enrolled in each group varied between 26.8 and 29.0 years of age. The ethnic/racial distribution varied between the five groups as follows: Caucasian: 77 - 90\%; Black: 4 - 15\%; Hispanic: 0 - 5\%; Asian: 0 - 4\%.

\section{Persistence of $S$. aureus carriage}

Results in Table 3 show that nasal carriage of $S$. aureus is more persistent (35.5\% and $41.0 \%$ groups 2 and 3 ) than vaginal or anal carriage, regardless of the strain. Vaginal and anal carriage of $S$. aureus is more transient (ranging from 55 to $77 \%$ of group) than nasal carriage. Seventeen subjects assigned to Group 4 (the negative control for $S$. aureus) were found to be culture-positive for non-toxigenic $S$. aureus and four of these showed persistent carriage.

\section{Persistence of serum antibody to TSST-1}

Serum antibody titers distributions from Group 1 and 2 (Figure 1) were found to be skewed toward higher titers during the follow up study, with the vast majority of visits showing titers $\geq 1: 64$. Carriers of non-toxigenic $S$. aureus (Group 3) and non-carriers (Group 4) (Figure 2) continued to show a broad distribution of antibody titers during the follow up study with antibody titers $\leq 1: 64$ at a significant number of visits. In total, twenty-one subjects in Groups 3, 4, and 5 became colonized with TSST-1 producing $S$. aureus during the course of the follow up study either by converting from non-toxigenic S. aureus or by acquiring a toxigenic $S$. aureus colony at one of the body sites. None of these subjects showed symptoms of toxic shock syndrome. In addition, these subjects were generally found to have sera anti-TSST-1 antibody distributions similar to carriers in Groups 1 and 2.

Five subjects from Group 5 seroconverted during the course of this study. Four subjects seroconverted between the end of the previous study [14] and the start of this study (approximately 1 year). One subject seroconverted between visit \#3 and visit \#4 of the follow up study (Table 4). Their ages ranged from 15 to 36, and none experienced TSS-like symptoms. No evidence of TSST-1 producing S. aureus was found in the body sites cultured from the four subjects, but it was detectable in the subject who converted between visit \#3 and visit \#4. This corresponded to the time interval in which serum anti-TSST-1 antibody titer increased from $\leq 1: 4$ to $1: 128$.

\section{Discussion}

Results of this study among healthy, menstruating women indicate that the distribution of carriage types vary more by body site than by the type of $S$. aureus strain (toxigenic or non-toxigenic). Nasal carriage of S. aureus appeared to be persistent ( $41 \%$ and $35.5 \%)$, whereas vaginal and anal carriage appeared to be more transient. Compared to findings from other studies summarized by VandenBergh [27], nasal carriage was more persistent in this study, which may be due to the fact that the subjects in these groups were selected based on their initial S. aureus carriage. A recent article by Nilsson and Ripa [36] determined the frequency and persistence of $S$. aureus colonization in the nose and throat in hospital patents and staff. These results demonstrated a nasal carriage rate of $31 \%$ and $36 \%$, respectively and a more frequent $S$. aureus throat colonization of $46 \%$ and $54 \%$.

Table 3 Classification of $S$. aureus colonization types in subjects completing a minimum of three subsequent visits

\begin{tabular}{|c|c|c|c|c|c|c|}
\hline $\begin{array}{c}\text { Group } \\
\text { No. }\end{array}$ & $\begin{array}{l}\text { Sample } \\
\text { location }\end{array}$ & S. aureus & $\begin{array}{c}\text { No. of } \\
\text { subjects }\end{array}$ & $\begin{array}{c}\% \text { Transient } \\
\text { carriers (\#subjects) } \\
\mathrm{Cl}^{\mathrm{a}}=0-24 \%\end{array}$ & $\begin{array}{c}\% \text { Intermittent } \\
\text { carriers (\#subjects) } \\
\mathrm{Cl}^{\mathrm{a}}=25-74 \%\end{array}$ & $\begin{array}{c}\% \text { Persistent } \\
\text { carriers (\#subjects) } \\
\mathrm{Cl}^{\mathrm{a}}=75-100 \%\end{array}$ \\
\hline 1 & Vagina & Toxigenic & 13 & $76.9 \%(10)$ & $23.1 \%(3)$ & $0 \%(0)$ \\
\hline 2 & Nasal & Toxigenic & 61 & $29.5 \%(18)$ & $29.5 \%(18)$ & $41.0 \%(25)$ \\
\hline 2 & Anal & Toxigenic & 12 & $66.7 \%(8)$ & $33.3 \%(4)$ & $0 \%(0)$ \\
\hline 3 & Vagina & Non-toxigenic & 22 & $54.5 \%(12)$ & $40.9 \%(9)$ & $4.5 \%(1)$ \\
\hline 3 & Nasal & Non-toxigenic & 31 & $29.0 \%(9)$ & $35.5 \%(11)$ & $35.5 \%(11)$ \\
\hline 3 & Anal & Non-toxigenic & 14 & $64.3 \%(9)$ & $28.6 \%(4)$ & $7.1 \%(1)$ \\
\hline 4 & Any site & Non-toxigenic & 58 & $70.7 \%(41)$ & $22.4 \%(13)$ & $6.9 \%(4)$ \\
\hline 4 & Any site & Toxigenic & 58 & $94.8 \%(55)$ & $5.2 \%(3)$ & $0 \%(0)$ \\
\hline
\end{tabular}

${ }^{\mathrm{a}} \mathrm{Cl}=$ carrier index, the number of swabs with positive culture of $S$. aureus relative to the total number of swabs taken $\times 100$ 


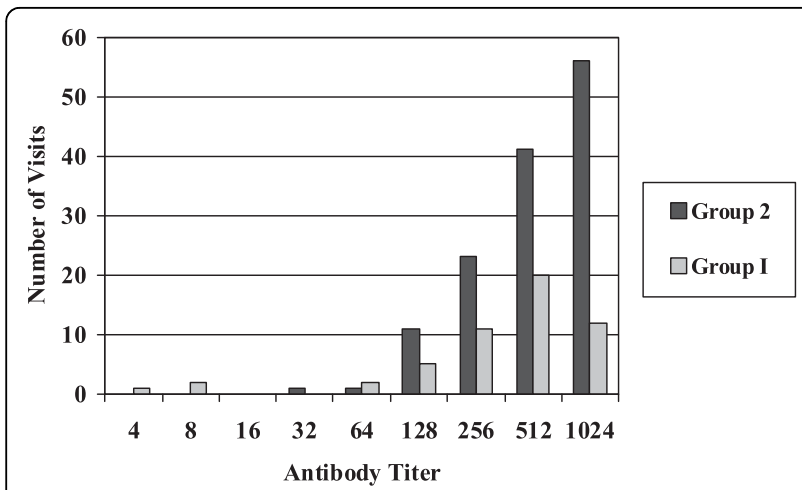

Figure 1 Anti-TSST-1 antibody titers for Groups 1 \& 2. A histogram of antibody titers expressed as a two-fold serial dilution starting at 1:4 to $\geq 1024$ versus total number of subject visits.

This may indicate the throat to be the primary source for subsequent $S$. aureus at other anatomical sites.

The higher persistence of $S$. aureus nasal carriage may reflect higher colonization of $S$. aureus in the nasal environment than the other body sites. Early experiments suggested that $S$. aureus binding to mucin may be critical for colonization of the nasophyngeal mucosa [37]. It has been suggested that the presence of type I cytokeratin 10 in the nasal epithelium allows clumping factor B (clfb) associated with $S$. aureus to bind to the epithelium and promote nasal colonization [38]. Another contributing factor to colonization frequency may be associated with human gene polymorphisms. An article published in 2006 by van den Akker [39] showed a clear association between persistent $S$. aureus nasal colonization and the glucocorticoid (GC) gene receptor. Carriers of the GC polymorphism were shown to increase the risk of persistent $S$. aureus nasal carriage by $80 \%$.

The absence of persistent carriage in the vagina may reflect low colonization due to the lack of type I

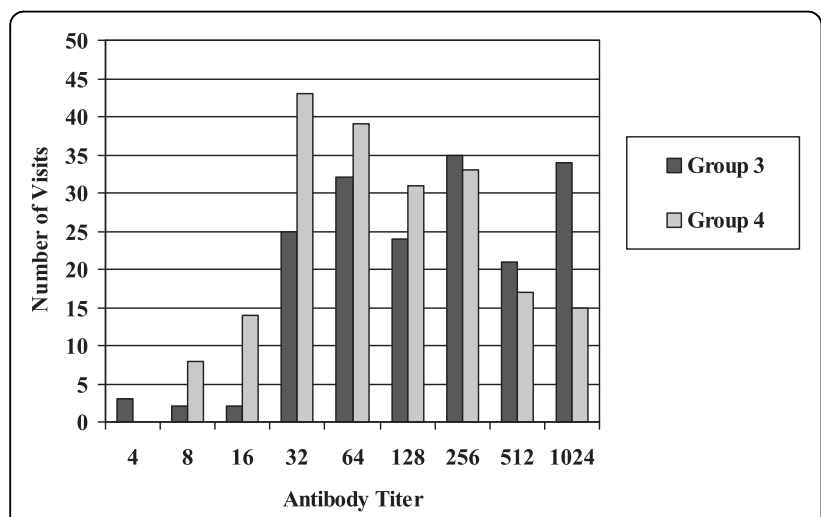

Figure 2 Anti-TSST-1 antibody titers for Groups 3 \& 4. A histogram of antibody titers expressed as a two-fold serial dilution starting at 1:4 to $\geq 1024$ versus total number of subject visits.
Table 4 Antibody titer by visit for subjects in Group 5 that seroconverted

\begin{tabular}{|c|c|c|c|c|}
\hline \multirow[t]{2}{*}{$\begin{array}{l}\text { Age of } \\
\text { subject }\end{array}$} & \multirow{2}{*}{$\begin{array}{c}A b^{a} \text { titer previous } \\
\text { study } \\
\text { Visit \#1 }\end{array}$} & \multicolumn{3}{|c|}{$\begin{array}{l}A b^{a} \text { titer during follow } \\
\text { up study }\end{array}$} \\
\hline & & $\begin{array}{c}\text { Visit } \\
\# 2\end{array}$ & $\begin{array}{c}\text { Visit } \\
\# 3\end{array}$ & $\begin{array}{c}\text { Visit } \\
\# 4\end{array}$ \\
\hline 15 & $\leq 1: 4$ & $1: 512$ & $1: 512$ & $1: 1024$ \\
\hline 18 & $\leq 1: 4$ & $1: 128$ & $1: 64$ & $1: 64$ \\
\hline 29 & $\leq 1: 4$ & $1: 64$ & $1: 64$ & N.C. ${ }^{b}$ \\
\hline 26 & $\leq 1: 4$ & $1: 128$ & $1: 128$ & $1: 512$ \\
\hline 36 & $\leq 1: 4$ & $\leq 1: 4$ & $\leq 1: 4$ & $1: 128^{c}$ \\
\hline
\end{tabular}

${ }^{\mathrm{a} A n t i-T S S T-1}$ antibody.

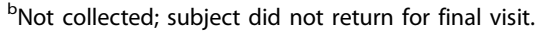

'TSST-1 producing S. aureus isolated from sample taken at this visit.

cytokeratin 10 in the mucosal epithelium or to changes in the vaginal environment during the menstrual cycle. Previous studies of vaginal biopsies using monoclonal antibodies showed the lack of cytokeratin 10 on the vaginal epithelium [C. Davis, A Kanti, M. Hansmann, J. Flood, C. Squier and J. Krueger, Abstr. Intersci. Conf. Antimicrob. Agents Chemother. abstr. B-1111, 2002]. Changes in the vaginal environment related to the menstrual cycle, such as levels of iron, $\mathrm{O}_{2}, \mathrm{CO}_{2}, \mathrm{pH}$, hormones [19-22], could also affect the total number of bacteria present or the number of colonizing species.

We speculate that the absence of persistent carriage in the anus may be related to lack of cytokeratin 10 binding sites (a marker associated with keratinizing cells) in the columnar epithelium, presence of intestinal mucus, and/or competition from the large population of microorganisms (including lactic acid bacteria) in the human intestine $[40,41]$.

The distribution of serum antibody titer among Group 1 subjects (Figure 1) was found to remain skewed toward higher titers during subsequent visits even though the number of positive culture isolations of toxigenic $S$. aureus dropped significantly during this part of the follow up study. This was also found to be true among Group 2 subjects (Figure 1); however, Group 2 also had a higher level of reisolation of toxigenic $S$. aureus during the subsequent visits. This seems to suggest that colonization at some point in time is sufficient to elevate antibody titers and those levels appear to be persistent. Antibody titer distributions among Groups 3 and 4 (Figure 2) showed trends similar to the original 3012 subjects' antibody titer distribution.

Five subjects with no initial serum antibody became seropositve (titer $\geq 1: 32$ ) over the course of the two and a half year study for a seroconversion rate of $7 \%$ of subjects. It is important to note that two of the five subjects were 18 years of age or younger. In addition, none of these subjects experienced TSS-like symptoms. These findings suggest that women can become seropositive at 
any stage of life and the serum antibody can develop as a result of environmental exposures that do not result in TSS-like symptoms.

\section{Conclusions}

Nasal carriage of $S$. aureus appeared to be persistent and the best predicator of subsequent colonization, whereas vaginal and anal carriage appeared to be more transient. It is interesting that at least $29.3 \%(17 / 58)$ of previous stated as non carriers showed to be positive during the follow up visits. This reinforces the concept that the carrier state for the human is not always absolute and this has been noted by other investigators [42]. A limitation of our study is that swab samples were analyzed in singlet, so that inter-observer variation in detection of $S$. aureus could not be determined; conventional methods for bacterial isolation and identification were employed, however, for which reason we are confident in the quality of our data.

Serum IgG levels against TSST- 1 has also been found to be higher in persistent carriers than in non-carriers of $S$. aureus[42]. From these findings, it appears that antibody titers in women found to be colonized with toxigenic $S$. aureus remained skewed toward higher titers whether or not the colonies were found to be persistent or transient in nature. This suggests that colonization at some point in time is sufficient to elevate antibody titer levels and those levels appear to be persistent. Results also indicate that women can become seropositive ( $7 \%$ seroconversion rate) without experiencing signs or symptoms of toxic shock syndrome.

Colonization of S. aureus TSST-1 and the absence of antibodies to TSST-1 are important in the pathogenesis of mTSS. Other factors not studied in the report include specific V beta 2 TCR ( $\mathrm{T}$ cell receptor) expansion and human leukocyte antigen (HLA) haplotype [43,44].

\section{Acknowledgements}

This work was sponsored by The Procter \& Gamble Company, Feminine Care Global Business Unit. We would like to thank Wendy Osterling and Matthew Lawlor (Channing Laboratory, Brigham \& Women's Hospital) and Wendy Weiland-Alter (Dartmouth-Hitchcock) for providing analysis used in this study, Anita L. Guy of ALG Technical Communications for assistance in preparing this manuscript, Catherine Davis (Procter \& Gamble) and Ron Berg (Procter \& Gamble) for technical review of the manuscript, Rita Reynolds (Procter \& Gamble) for providing data management of the clinical data and Bambi Steimle (Procter \& Gamble) for providing classification analysis of the clinical data.

\section{Author details}

'Dartmouth-Hitchcock Medical Center, One Medical Center Drive, Lebanon, New Hampshire, USA. ${ }^{2}$ Channing Laboratory, Brigham \& Women's Hospital, Harvard Medical School, 181 Longwood Ave, Boston, Massachusetts, USA. ${ }^{3}$ The Procter \& Gamble Company, 6010 Center Hill Ave., Cincinnati, Ohio, USA. ${ }^{4}$ Hill Top Research Inc., Main \& Mill St., Miamiville, Ohio, USA.

\section{Authors' contributions}

JP was Co-investigator and provided data interpretation. AO was COinvestigator and provided data interpretation. JW was a co-investigator and provided clinical support of the trial. MH provided study design \& clinical support. JS provided study design \& clinical support. MD provided microbiological support. AD provided microbiological support. PM provided antibody titer analyses. MJ provided statistical analyses. All authors read and approved the final manuscript.

\section{Competing interests}

JP: Received a grant for this research work.

MH: Is an employee of the Procter \& Gamble Co and holds shares of stock in Procter \& Gamble.

JLS: Is a retired employee of the Procter \& Gamble Co and holds shares of stock in Procter \& Gamble.

MLD: Received a grant for this research work.

AMD: Received a grant for this research work.

PAM: Received a grant for this research work.

MBJ: Is a retired employee of the Procter \& Gamble Co and holds shares of stock in Procter \& Gamble.

JEW: Hilltop Research received financial support for clinical work. JEW was employed as the clinical investigator and executed the clinical portion of the study.

ABO: Received a grant for this research work.

Received: 24 August 2009 Accepted: 23 August 2010

Published: 23 August 2010

\section{References}

1. Chesney PJ: Clinical aspects and spectrum of illness of toxic shock syndrome: overview. Rev Infect Dis 1989, 11(Suppl 1):S1-S7.

2. Gaventa S, Reingold AL, Hightower AW, Broome CV, Schwartz B, Hoppe C, Harwell J, Lefkowitz LK, Makintubee S, Cundiff DR, Sitze S, the Toxic Shock Syndrome Study Group: Active surveillance for toxic shock syndrome in the United States, 1986. Rev Infect Dis 1989, 11(Suppl 1):S28-S34.

3. Todd JK, Wisenthal AM, Ressman M, Caston SA, Hopkins RS: Toxic shock syndrome II. Estimated occurrence in Colorado as influenced by case ascertainment methods. Am J Epidemiol 1985, 122:857-867.

4. Descloux E, Perpoint T, Ferry T, Lina G, Bes M, Vandenesch F, Mohammedi I, Etienne J: One in five mortality in non-menstrual toxic shock syndrome versus no mortality in menstrual cases in a balanced French series of 55 cases. Eur J Clin Microbiol Infect Dis 2008, 27(1):37-43.

5. Garbe PL, Arko RL, Reingold AL, Graves LM, Hayes PS, Hightower AW, Chandler FW, Broome CV: Staphylococcus aureus isolates form patients with non-menstrual toxic shock syndrome. Evidence for additional toxins. JAMA 1985, 253:2538.

6. Czerwinski BS: Variation in feminine hygiene practices as a function of age. J Obstet Gynecol Neonatal Nurs 2000, 29:625-33.

7. Nelson E, Jordan M: Sensitive Export: Seeking New Markets for Tampons, P\&G Faces Cultural Barriers. The Wall Street Journal 2000, A1.

8. Bergdoll MS, Crass BA, Reiser RF, Robbins RN, Lee AC, Chesney PJ, Davis JP, Vergeront JM, Wand PJ: An enterotoxin-like protein in Staphylococcus aureus strains from patients with toxic shock syndrome. Ann Intern Med 1982, 96:969-971.

9. Schlievert PM, Shands KN, Dan BB, Schmid GP, Nishimura RD: Identification and characterization of an exotoxin from Staphylococcus aureus associated with toxic-shock syndrome. J Infect Dis 1981, 143:509-516.

10. Norrby-Teglund A, Chatellier S, Low DE, McGeer A, Green K, Kotb M: Host variation in cytokine responses to superantigens determine the severity of invasive group A streptococcal infection. Eur J Immunol 2000, 30:3247-3255.

11. Kotb M, Norrby-Teglund A, McGeer A, El-Sherbini H, Dorak MT, Khurshid A, Green K, Peeples J, Wade J, Thomson G, Schwartz B, Low DE: An immunogenetic and molecular basis for differences in outcomes of invasive group A streptococcal infections. Nat Med 2002, 8:1398-1404.

12. Norrby-Teglund A, Kaul R, Low DE, McGeer A, Newton DW, Andersson J, Andersson $U$, Kotb M: Plasma from patients with severe invasive group $A$ 
streptococcal infections treated with normal polyspecific lgG inhibits streptococcal superantigen-induced T cell proliferation and cytokine production. J Immunol 1996, 156:3057-3064

13. Basma H, Norrby-Teglund A, Guedez Y, McGeer A, Low DE, El-Ahmedy O, Schwartz B, Kotb M: Risk factors in the pathogenesis of invasive group A streptococcal infections: role of protective humoral immunity. Infect Immun 1999, 67:1871-1877.

14. Parsonnet J, Hansmann MA, Delaney ML, Modern PA, DuBois AM, WielandAlter W, Wissemann KW, Wild JE, Jones MB, Seymour JL, Onderdonk AB: Prevalence of toxic shock syndrome toxin-1 producing Staphylococcus aureus and the presence of antibodies to this superantigen in menstruating women. J Clin Micro 2005, 43:4628-4634.

15. Parsonnet J, Sullivan C, Modern P, Wissemann K: Risk factors for TSS among European women: vaginal colonization with $S$. aureus and antibody to TSST-1. In Proceedings of the European conference on toxic shock syndrome. Edited by: Arbuthnott J, Furman B. London, The Royal Society of Medicine Press, Ltd; 1997:72.

16. Adesium AA, Singh D, Guness Rl: Toxic shock syndrome toxin-1 (TSST-1) production and phage susceptibility of Staphylococcus aureus strains from human vaginas and anterior nares in Trinidad. Zentralbl Bakteriol 1994, 280:371-381.

17. Chow AW, Bartlett KH, Percival-Smith R, Morrison BJ: Vaginal colonization with Staphylococcus aureus, positive for toxic-shock marker protein, and Escherichia coli in healthy women. J Infect Dis 1984, 150:80-84.

18. Linnemann CC Jr, Staneck JL, Hornstein S, Barden TP, Rauh JL, Boneventre PF, Buncher CR, Benting A: The epidemiology of genital colonization with Staphylococcus aureus. Ann Intern Med 1982, 96:940-944.

19. Yarwood JM, Schlievert PM: Oxygen and carbon dioxide: Regulation of toxic shock syndrome toxin 1 production by Staphylococcus aureus MN8. J Clin Microbiol 2000, 38(5):1797-1803.

20. Sarafian SK, Morse SA: Environmental factors affecting toxic shock syndrome toxin-1 (TSST-1) synthesis. J Med Microbio 1987, 24:75-81.

21. Taylor $\mathrm{D}$, Holland $\mathrm{KT}$ : Effect of dilution rate and $\mathrm{Mg}+2$ limitation on toxic shock syndrome toxin-1 production by Staphylococcus aureus grown in defined continuous culture. J Gen Microbiol 1988, 134:719-723.

22. Wong AC, Bergdoll MS: Effect of environmental conditions on production of toxic shock syndrome toxin 1 by Staphylococcus aureus. Infect Immun 1990, 58:1026-1029.

23. Davis CC, Kremer MJ, Schlievert PM, Squier CA: Penetration of toxic shock syndrome toxin-1 across porcine vaginal mucosa ex vivo: permeability characteristics, toxin distribution and tissue damage. Am J Obstet Gynecol 2003, 189:1785-1791.

24. Bonventre PF, Thompson MR, Adinolfi LE, Gillis ZA, Parsonnet J: Neutralization of toxic shock syndrome toxin- 1 by monoclonal antibodies in vitro and in vivo. Infect Immun 1998, 56(1):135-41.

25. Vergeront JM, Stolz SJ, Crass BA, Nelson DB, Davis JP, Bergdoll MS: Prevalence of serum antibody to staphyloccocal enterotoxin $\mathrm{F}$ among Wisconsin residents: implications for toxic-shock syndrome. $J$ Infect Dis 1983, 148:692-698.

26. Jacobson JA, Kasworm EM, Crass BA, Bergdoll MS: Nasal carriage of toxigenic Staphylococcus aureus and prevalence of serum antibody to toxic-shock-syndrome toxin 1 in Utah. J Infect Dis 1986, 153:356-359.

27. VandenBergh MFQ, Yzerman EPF, van Belkum A, Boelens HAM, Sijmons M, Verbrugh HA: Follow-up of Staphylococcus aureus nasal carriage after 8 years: redefining the persistent carrier state. J Clin Micro 1999, 37(10):3133-3140.

28. Peacock SJ, Justice A, Griffiths D, de Silva GDI, Kantzanou MN, Crook D, Sleeman K, Day NPJ: Determinants of acquisition and carriage of Staphylococcus aureus in infancy. J Clin Micro 2003, 41(12):5718-5725

29. Kuehnert MJ, Kruszon-Moran D, Hill HA, McQuillan G, McAllister SK, Fosheim G, McDougal LK, Chaitram J, Jensen B, Fridkin SK, Killgore G, Tenover FC: Prevalence of Staphylococcus aureus nasal colonization in the United States, 2001-2002. J Infect Dis 2006, 193:172-179.

30. Nouwen J, Boelens $\mathrm{H}$, van Belkum A, Verbrugh $\mathrm{H}$ : Human factor in Staphylococcus aureus nasal carriage. Infect Immun 2004, 72(11):6685-6688

31. Nouwen JL, Ott A, Kluytmans-Vandenbergh MFQ, Boelens HAM, Hofman A, van Belkum A, Verbrugh H: Predicting the Staphylococcus aureus nasal carrier state: derviation and validation of a "culture rule". Clin Infect Dis 2004, 39:806-811.

32. Kansal R, Davis C, Hansmann M, Seymour J, Parsonnet J, Modern P, Gilbert S, Kotb M: Structural and Functional Properties of Antibodies to the Superantigen TSST-1 and Their Relationship to Menstrual Toxic Shock Syndrome. J Clin Immunol 2007, 27(3):327-338.

33. Tavares D, Sa-Leo R, Miragaia M, Lencastre H: Large screening of CA-MRSA among Staphylococcus aureus colonizing healthy young children living in two areas (urban and rural) of Portugal. BMC Infectious Diseases 2010, 110.

34. Parsonnet J, Mills JT, Gillis ZA, Pier GB: Competitive, enzyme-linked immunosorbent assay for toxic shock syndrome toxin-1. J Clin Microbiol 1985, 22:26-31.

35. Johnson WM, Tyler SD: PCR Detection of genes for enterotoxins, exfoliative toxins, and toxic shock syndrome toxin-1 in Staphylococcus aureus. In Diagnostic molecular microbiology principles and applications. Edited by: Persing DM, Smith TF, Tenover FC, White TJ. Rochester MN, American Society for Microbiology; 1993:294-299.

36. Nilsson P, Ripa T: Staphylococcus aureus Throat Colonization Is More Frequent than Colonization in the Anterior Nares. J Clin Micro 2006, 44(9):3334-3339.

37. Shuter V, Hatcher B, Lowy FD: Staphylococcus aureus binding to human nasal mucin. Infect Immun 1996, 64(1):310-318.

38. Walsh EJ, O'Brien LM, Liang $X$, Hooks M, Foster TJ: Clumping factor B, a fibrinogen-binding MSCRAMM (microbial surface components recognizing adhesive matrix molecules) adhesin of Staphylococcus aureus, also binds to the tail region of type I cytokeratin 10. Journal of Chemistry 2004, 279(49):50691-50699.

39. van den Akker ELT, Nouwen JL, Melles DC, van Rossum EFC, Koper JW, Uitterlinden AG, Hofman A, Verbrugh HA, Pols HA, Lamberts SWJ, Van Belkum A: Staphylococcus aureus nasal carriage is associated with glucocorticoid receptor gene polymorphisms. J Infect Dis 2006, 194:814-818.

40. Vesterlund S, Karp M, Salminen S, Ouwehand AC: Staphylococcus aureus adheres to human intenstinal mucus but can be displaced by certain lactic acid bacteria. Microbiology 2006, 152:1819-1826.

41. Gill SR, Pop M, DeBoy RT, Eckburg PB, Turnbaugh PJ, Samuel BS, Gordon Jl, Relman DA, Fraser-Liggett CM, Nelson KE: Metagenomic analysis of the human distal gut microbiome. Science 2006, 312:1355-1359.

42. van Belkum A, Verkaik NJ, de Vogel CP, Boelens HA, Verveer J, Nouwen JL, Verbrugh HA, Werthiem HFL: Reclassification of Staphylococcus aureus nasal carriage types. J Infect Dis 2009, 199:1820-1826.

43. Thomas D, Dauwalder O, Brun V, Badiou C, Ferry T, Etienne J, Vandenesch F, Lina G: Staphylococcus aureus Superantigens Elicit Redundant and Extensive Human VB Patterns. Infect Immun 2009, 77(5):2043-2050.

44. Kotb M, Norrby-Teglund A, McGeer A, El-Sherbini H, Dorak MT, Kurshid A, Green K, Peeples J, Wade J, Thomson G, Schwartz B, Low DE: An immunogenetics and molecular basis for differences in outcomes of invasive group A streptococcal infections. Nat Med 2002, 8(12):1398-1404.

\section{Pre-publication history}

The pre-publication history for this paper can be accessed here: http://www.biomedcentral.com/1471-2334/10/249/prepub

doi:10.1186/1471-2334-10-249

Cite this article as: Parsonnet et al:. Persistence survey of Toxic Shock Syndrome toxin-1 producing Staphylococcus aureus and serum antibodies to this superantigen in five groups of menstruating women. BMC Infectious Diseases 2010 10:249.

\section{Submit your next manuscript to BioMed Central and take full advantage of:}

- Convenient online submission

- Thorough peer review

- No space constraints or color figure charges

- Immediate publication on acceptance

- Inclusion in PubMed, CAS, Scopus and Google Scholar

- Research which is freely available for redistribution 